\section{Low-temperature Exotherm Measurement Using Infrared Thermography}

Toni L. Ceccardi

University of Florida, Institute of Food and Agricultural Sciences, Citrus Research and Education Center, 700 Experiment Station Road, Lake Alfred, FL 33850

\section{Robert L. Heath and Irwin P. Ting \\ Department of Botany and Plant Sciences, University of California, Riverside, CA 92521-0124}

Additional index words. Simmondsia chinensis, jojoba, differential thermal analysis, thermoelectric module

\begin{abstract}
Infrared thermography was used successfully to measure the exotherm temperatures during freezing of well-watered and drought-stressed branches of jojoba [Simmondsia chinensis (Link) Schneider]. The exotherms were visualized easily as color changes on the monitor, while computer analysis software was used to plot the resulting temperature vs. time curves, suggesting that freezing sensitivity of jojoba is governed by supercooling. Each branch froze as a unit, and distinct initiation sites were absent. A second, previously tested method of differential thermal analysis was used simultaneously and confirmed the accuracy of the infrared technique. The actual freezing temperature for well-watered tissue was higher $(-8 C)$ than for tissue subjected to drought $(-10 C)$.
\end{abstract}

A new technique, using infrared thermography, was tested to visualize the changes in surface temperature of jojoba leaves and stems during ice formation. The exothermic event of ice formation is more commonly measured by differential thermal analysis (DTA) using thermocouples or thermoelectric modules (TEMs) (Andrews et al., 1983; George et al., 1974). Studies with thermocouples usually require that the tissue be pierced with the thermocouple, or that small organs be dissected before attachment to thermocouples (Quamme, 1978). These techniques may lead to inaccurate measurements of freezing points (Wample et al., 1990). In our experiments, the heat released during ice formation was visualized by videotaping the output of an infrared video camera. A measurement of a single branch end by TEMs showed that the heat release due to ice formation occurred at the same temperature as that observed for an entire branch by infrared thermography.

Jojoba is an industrial crop cultivated in regions that are subjected to frosts. Although the tissue tends to supercool, frosts can frequently injure young tissue. Small exposed organs of the plant, such as flower buds, are particularly sensitive to low temperature. Thus, we were interested to learn if freezing, beginning in the youngest, smallest buds and leaves,

Received for publication 6 June 1994. Accepted for publication 4 Oct. 1994. We thank Ruby Miller for technical assistance with the infrared apparatus and software. The cost of publishing this paper was defrayed in part by the payment of page charges. Under postal regulations, this paper therefore must be hereby marked advertisement solely to indicate this fact. tion or if after the minimum supercooling temperature is reached, the tissue froze as a unit (Sakai and Larcher, 1987). Our experimental objective was to find a technique to visualize ice initiation in individual organs using a noninvasive method, i.e., infrared imaging, for measuring exotherm temperatures in intact plants.

\section{Materials and Methods}

Jojoba plants grown in growth chambers were kept under 9-h daylengths and a 15/5C day/night cycle. Six plants of the genotypic selection 'Vista' were kept wet or dry (watered every 3 or 5 days; three plants in each treatment).

For freezing analysis, one branch was selected and removed from a plant of each irrigation treatment, placed into a chest freezer (Kenmore 23; Sears Roebuck and Co., Chicago), and fixed against a styrofoam background. The branches were four nodes $(\approx 9 \mathrm{~cm})$ long and had eight (wet) or 12 leaves, including one lateral branch (dry). The freezer was modified to run under the control of a computer (portable IBM PC) equipped with a DAS-8 I/O board (Keithley Metrabyte Corp., Taunton, Mass.) similar to that described in Wample et al. (1990). The infrared video camera (model 600 IR Imaging Radiometer; Inframetrics, Billerica, Mass.) was preequilibrated at $4 \mathrm{C}$, placed inside the freezer, and focused on the two branches. The false color image of the branches was videotaped as the freezer temperature was lowered from 0 to

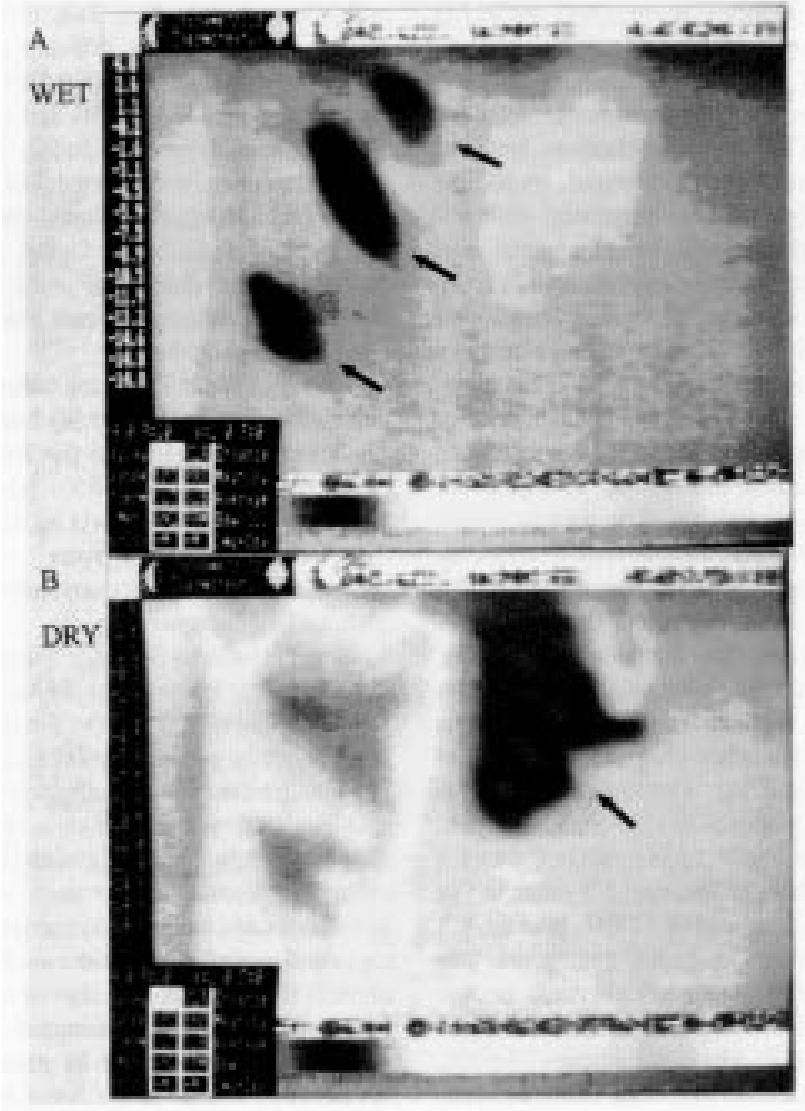

Fig. 1. Exotherms of wet and dry jojoba, as visualized with infrared imaging. The black areas are the leaves that are warmer than the background during exotherms. The arrows identify the parts of (A) the wet branch and (B) the dry branch. 
$-12 \mathrm{C}$ at a rate of $2 \mathrm{C} / \mathrm{h}$. At the same time, TEMs (CP1.0-127-05L; Melcor Thermoelectrics, Trenton, N.J.) were attached at the base of the videotaped branches for DTA to measure the temperature at which the exotherms occurred (Wample et al., 1990). The TEMs were held in place by sandwiching the TEM and stem between insulating squares of foam and cardboard and wrapping them together with parafilm. They were monitored in 30-sec sample intervals with a data digitizer (EXP16, DAS-8 I/O board; Keithley Metrabyte Corp.) and the output was recorded on a diskette.

\section{Results and Discussion}

With infrared imaging, the exotherms of the wet (Fig. 1A) and dry (Fig. 1B) branches appeared as vibrant changes in color and contrast between the branch and the background, as the branch temperatures were up to $3 \mathrm{C}$ higher than that of the background (Fig. 1). The duration of the exotherm, as indicated by branch temperatures higher than the background, lasted up to $20 \mathrm{~min}$. During these 20 min, the change in freezer temperature was only $0.5 \mathrm{C}$. The corresponding time vs. temperature curves generated from a single point on each branch (calculated by the infrared software ThermaGRAM ver. 2.0, Thermoteknix Systems, Cambridge, U.K., and Lotus 3.1 spreadsheet) clearly showed peaks, indicating that exotherms occurred and that exotherm of the dry stem occurred at a later time than that of the wet one (Fig. 2). Infrared images are stored permanently on video cassette tapes, and the data can be replayed and analyzed using different areas on the branch or leaf. After analyzing several points on each branch, there appeared to be no delay in ice formation between younger and older tissue. Therefore, we conclude that jojoba branches froze as a unit. The same information, as recorded from the output of the TEMs, shows that the wellwatered branch froze at a higher temperature than the dry branch (Fig. 3). Many repetitions of the freezing studies with TEMs were performed (not shown). For detached branches as used in this study, the standard errors were $\approx 0.5 \mathrm{C}$ with the TEM method (Ceccardi, 1993). The infrared method was repeated three times using different jojoba agronomic selections; therefore, the results could not be compared to each other, but only to the corresponding TEM data, to which they always showed excellent correlation (not shown). The fluctuations in the freezer temperature of $\approx 1 \mathrm{C}$ (Fig. 3) were due to the incapability of the compressor to toggle on and off rapidly and maintain a flat baseline. Rapid switching caused a shutdown of our freezer, so a delay was written into our modification of the Wample et al. (1990) program. This noise could be avoided by using more sophisticated equipment, such as that used by Wample et al. (1990).

Infrared imaging also may be useful for visualizing freezing in an intact plant, especially one that undergoes multiple exotherms. Ashworth (1982) described peach [Prunus persica (L.) Batsch] flower bud freezing as

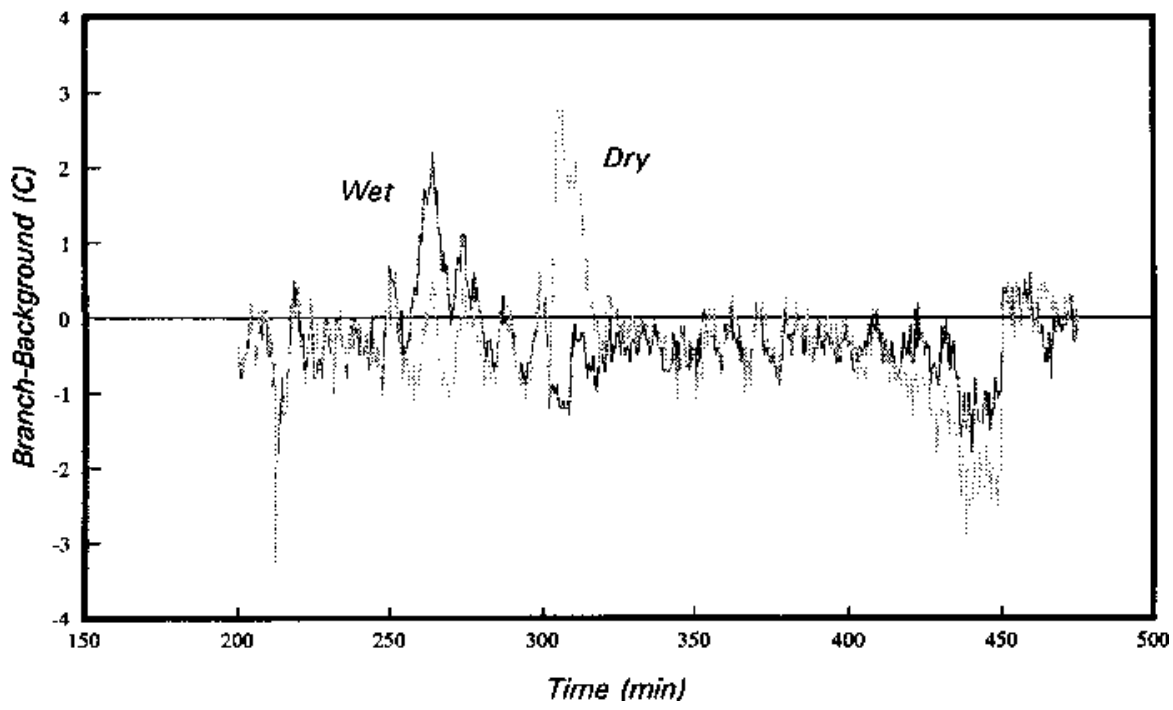

Fig. 2. Infrared imaging software analysis of time vs. temperature for the wet and dry jojoba branches. The peaks indicate where the branch temperatures increased above the background temperature. The wet branch froze at $\approx 250 \mathrm{~min}$, and the dry one froze $\approx 50 \mathrm{~min}$ later. Because the temperatures were plotted as a differential, they fluctuate around zero, although the actual temperature was decreasing to $-12 \mathrm{C}$. The actual temperatures can also be plotted or can be viewed on a video monitor.

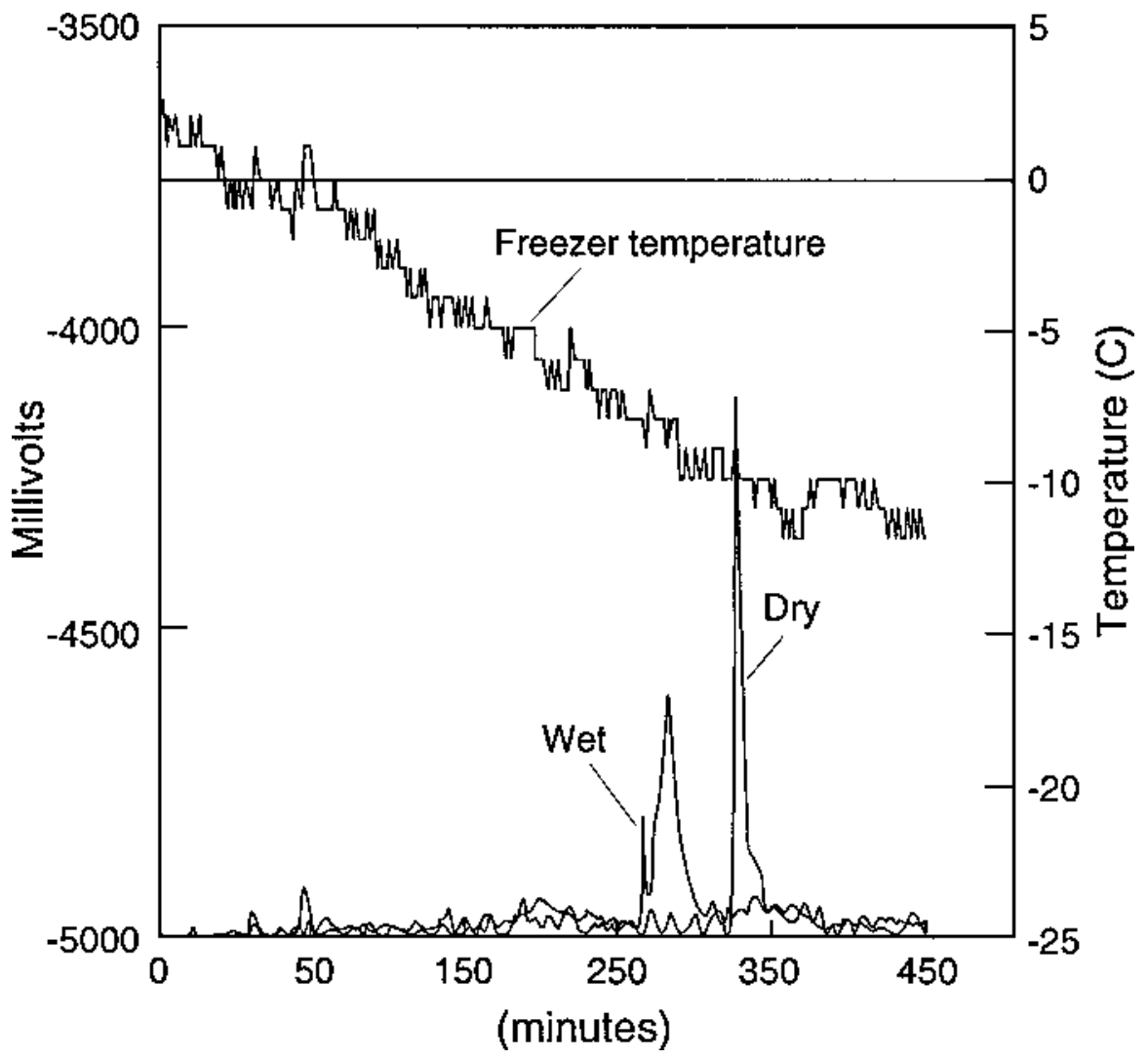

Fig. 3. Exothermic data as measured with thermoelectric module, analyzed using Lotus 1-2-3 and a program modified from Wample et al. (1990). The sloped curve shows the descending freezer temperature. The peaks in voltage output indicate exothermic events in the branches, showing that the wet branch froze at about $-8 \mathrm{C}$ and the dry branch at about $-10 \mathrm{C}$.

occurring in two distinct exothermic events: first the axis tissues freeze at a high temperature, then the primordial tissues freeze at a lower temperature. Such distinct exothermic events likely can be visualized using infrared imaging. Additionally, exotherm maxima, the highest temperature reached as heat is released during freezing, which in a supercooling plant is the actual freezing point (Anderson et al., 1983; Yelenosky and Horanic, 1969), are easily measured (as the time differential of the temperature data). The equipment can be easily transported and is battery-operated; therefore, it could be used in limited field experiments. The camera itself can be subjected to subfreezing temperatures without harm. 


\section{Miscellaneous}

\section{Literature Cited}

Anderson, J.A., D.W. Buchanan, and M.J. Burke. 1983. Freeze tolerance vs. freeze avoidance in citrus leaves. Proc. Fla. State Hort. Soc. 96:57-58.

Andrews, P.K., E.L. Proebsting, and D.C. Gross. 1983. Differential thermal analysis and freezing injury of deacclimating peach and sweet cherry reproductive organs. J. Amer. Soc. Hort. Sci. 108:755-759.

Ashworth, E.N. 1982. Properties of peach flower buds which facilitate supercooling. Plant Physiol. 70:1475-1479.

Ceccardi, T.L. 1993. The effects of drought on the frost resistance of Simmondsia chinensis. $\mathrm{PhD}$ Diss., Univ. of California, Riverside.

George, M.F., M.J. Burke, and C.J. Weiser. 1974. Supercooling in overwintering azalea flower buds. Plant Physiol. 54:29-35.

Quamme, H.A. 1978. Mechanism of supercooling in overwintering peach flower buds. J. Amer. Soc. Hort. Sci. 103:57-61.
Sakai, A. and W. Larcher. 1987. Frost survival of plants. Responses and adaptation to freezing stress. Springer-Verlag, Berlin.

Wample, R.L., G. Reisenauer, A. Bary, and F. Schuetze. 1990. Microcomputer-controlled freezing, data acquisition, and analysis system for cold hardiness evaluation. HortScience 25:973-976.

Yelenosky, G. and G. Horanic. 1969. Subcooling in wood of citrus seedlings. Cryobiology 5:281283. 